EUROPEAN ORGANIZATION FOR NUCLEAR RESEARCH

\title{
ELECTRON DRIFT VELOCITY AND CHARACTERISTICS OF IONIZATION OF ALPHA AND BETA PARTICLES IN LIQUID ARGON DOPED WITH ETHYLENE FOR LHC CALORIMETRY
}

\author{
V. Vuillemin , P. Cennini , C.W. Fabjan, D. Lacarrère, A. Looten , \\ M. Moulson* and W. Seidl \\ CERN, Geneva, Switzerland \\ P. Carlson, W. Klamra , Th. Lindblad and B. Lund-Jensen \\ Manne Siegbahn Institute of Physics, Stockholm, Sweden
}

\begin{abstract}
:
Drift velocity and charge response to $\alpha$ and $\beta$ particles of liquid argon doped with $200 \mathrm{ppm}$ to $0.5 \%$ (vol.) of ethylene have been studied. The addition of ethylene increases the drift velocity by at least a factor of 2 , and at low concentrations, improves the collected charge of $\alpha$ particles through photoionization. At larger concentrations, a degradation of the saturation properties of the mixture is observed. The present results demonstrate that simultaneous improvement of drift velocity and compensation in hadron calorimetry is incompatible. The consequences of using doped liquid argon for the Large Hadron Collider (LHC) detectors in the high radiation environment are discussed.
\end{abstract}

Visitor from Columbia University, New York, NY, USA. 


\section{Introduction}

Precision calorimetry will be an essential detection technique for the Large Hadron Collider (LHC) experiments [1]. The liquid-argon ionization chamber method is widely regarded as very promising, since this technique is usually considered as giving very good control of systematic effects. On the other hand, the drift-time [2] and incomplete compensation [3] may provide a limit to its application at the LHC.

The LHC parameters allow a luminosity of $3 \times 10^{34} \mathrm{~cm}^{-2} \mathrm{~s}^{-1}$ to be reached at a bunch-crossing frequency of 1 per 15 ns [4]. Such conditions impose severe requirements on detectors in terms of granularity [5], speed of response [6], and radiation resistance [7]. An interbunch time separation of $15 \mathrm{~ns}$ should be compared to the total drift-time of free electrons crossing a $2 \mathrm{~mm}$ gap of approximately $450 \mathrm{~ns}$. During this drift-time, events from 30 bunch crossings will 'pile-up' in the calorimeter.

The effect of this pile-up can be reduced by using very fast shaping in the signal-processing electronics. However, fast shaping is accompanied by the loss of collected charge as well as by the inevitable increase in the electronic noise $[8]$.

An increase in the drift velocity of electrons in liquid Ar by a factor of 2 or more above the saturated pure liquid $\mathrm{Ar}$ velocity would be desirable for the LHC calorimeters. For a given shaping time, a higher drift speed will lead to an effective increase in the collected charge. It has been known for some time [9] that the addition of molecular solutes such as hydrocarbons at the level of a fraction of a percent increases the drift velicity above the saturation value of liquid Ar at high electric fields. Factors of two or more have been obtained in several test cells and recently confirmed in a large calorimeter with the addition of $0.35 \%$ methane [3].

Saturation effects in the charge collection are produced in liquid Ar from the interactions of heavily ionizing particles, such as slow protons, alpha particles or heavy ions $[10]$. In this case, recombination of electrons and ions predominates, and a large fraction of the energy is lost through scintillation light emitted in the UV region $(130 \mathrm{~nm})$. Ultraviolet luminescence from liquid argon has been studied extensively [11]. It has been shown that for liquid Ar, 67\% of 
the luminescence is due to excited molecules which are produced through the recombination of molecular ions and free electrons and that $33 \%$ is due to the de-excitation of self-trapped excitons by UV emission. The recombination process is field dependent, whereas luminescence coming from excitons is independent of the electric field.

Photosensitive dopants will increase the charge collection in a liquid $\mathrm{Ar}$ calorimeter by converting the scintillation light into detectable charge $[11,12]$. The response to densely ionizing particles is especially improved owing to the large luminescence yield. The luminescence in liquid Ar has two components, a fast one with a decay time of $5 \mathrm{~ns}$ and a slow one with a decay time of $1.1 \mu \mathrm{s}$, coming from the decay of singlet and triplet exciton states, respectively, whose lifetimes are very different. It is clear that high-rate operation using liquid $\mathrm{Ar}$ luminescence (through the addition of photosensitive dopants) requires the slow component to be quenched [13].

So far, all known photosensitive dopants have been added to liquid Ar in very small concentrations. At such a level (a few ppm), no significant increase of the drift velocity is expected. One might hope that a sufficient amount of photosensitive dopant can be added to liquid Ar in order to improve on both the saturation effects for better compensation and the drift speed of electrons. However, most of the photosensitive dopants have very poor solubilities at the temperature of liquid Ar. Ethylene $\left(\mathrm{C}_{2} \mathrm{H}_{4}\right)$ is to our knowledge the only nonpolar molecule which is at the same time photosensitive [14] and soluble enough in liquid $\mathrm{Ar}$ to increase the drift velocity by a factor of $2[15]$.

In Section 2, the solubility of some unsaturated hydrocarbons in liquid $\mathrm{Ar}$ is discussed. Most of the unsaturated hydrocarbons have ionization potentials low enough to be photoionized by licpuid Ar luminescence. The experimental test set-up is described in Section 3. The results of the measurements on drift velocity and charge collection from both $\alpha$ and $f$ sources in ethylene-doped liquid Ar are presented in Section 4 and discussed in Section 5.

Monitoring of the different constants characterizing the energy response of a LHC calorimeter is essential. In Section 6, the implications on the systematics of adding a solute such as ethylene to pure liquid Ar are described. In Section 7, radiation damage to ethylene is discussed. 


\section{Maximum solubility and ionization potential}

Data are available on the solubilities of hydrocarbons in liquid oxygen [15]. Around a temperature of $90 \mathrm{~K}$, these results give an indication of the expected solubilities of such substances in liquid Ar, provided that no specific reaction would differentiate argon from oxygen, i.e., provided that temperature is the main parameter controlling maximum solubility. The data on unsaturated hydrocarbons are summarized in Table 1.

The solubilities of substances in liquid Ar have not been essential concerns so far, since very small quantities of photosensitive dopants are sufficient to obtain substantial increases in collected charge. To increase the drift velocity of electrons, however, requires a much higher dopant concentration.

Beatie et al. [16] show that maximum solubility follows the relation:

$$
\ln (\text { solubility }) \approx\left(1 / T_{\mathrm{mp}}-1 / T_{\mathrm{op}}\right)
$$

where :

$T_{\mathrm{mp}}$ is the melting point of the solute, i.e., the dopant

$T_{\mathrm{op}}$ is the temperature of operation, approximately $90 \mathrm{~K}$ for liquid $\mathrm{Ar}$.

Most of the dopants freeze at liquid Ar temperature; consequently their maximum solubilities are functions of the differences between their meltingpoint temperatures and the temperature of operation. Constants involved in the equation and not shown here are the heat of fusion of the solute at its freezing temperature and the effective heat of solution.

Figure 1 shows the maximum observed molar concentrations at $90 \mathrm{~K}$ in liquid $\mathrm{O}_{2}$ for the unsaturated hydrocarbons. Ethylene and propylene have the highest solubilities around 1\% maximum concentration. The maximum solubility of ethylene is superior to that of propylene. From the comparison of melting points alone, one would expect the reverse situation. Maximum solubility also varies with the number of carbon atoms in the molecule, as shown in Fig. 2. Almost all of the solubilities of the compounds lie on a line on a semilog plot as a function of $\mathrm{N}$ (C-atoms), except acetylene, whose melting point is much higher than those of the other molecules. 
In liquid Ar, the energy necessary to extract an electron from a photosensitive substance is lowered by $0.7 \mathrm{eV}$ [12]. As the luminescence of $\mathrm{Ar}$ peaks at $130 \mathrm{~nm}$, corresponding to $9.5 \mathrm{eV}$, all substances whose ionization potential is lower than $10.2 \mathrm{eV}$ are potential candidates for photosensitive dopants. Ionization quantum efficiencies of pure unsaturated hydrocarbons have been measured as functions of wavelength [14,17]. Effective ionization efficiencies for such substances in liquid Ar can thus be estimated.

A summary of the relevant parameters concerning some dopants is given in Table 2. From this table some conclusions can be drawn on the potential of photosensitive substances to increase the drift speed of free electrons:

i) ethylene is a good candidate;

ii) propylene is also, but it is a polar molecule,

iii) allene has the highest quantum efficiency but its solubility is unlikely to exceed $400-500 \mathrm{ppm}$,

iv) other unsaturated hydrocarbons do not seem to present advantages over these three candidates.

The increase of the drift speed due to ethylene or propylene is very similar and reaches a factor of two at a concentration of $0.2 \%$.

\section{Experimental set-up}

A test chamber has been designed $[18]$ in order to measure in a single liquid volume all of the relevant parameters related to ionization, such as:

i) the collected charge,

ii) the drift velocity,

iii) the lifetime of the mixture.

These parameters depend on the dopant concentration as well as on the amount of impurities dissolved in the liquid. These parameters can be measured in three different ways: radioactive sources, photoproduction of free electrons in the drift gap by a UV laser, and IR spectroscopy to detect impurities and measure dopant concentrations. 
The effect of the dopants as a function of the ionization density can be evaluated with $\alpha$ and $\beta$ particles. For the present set-up we use both sources, $241 \mathrm{Am}$ for 0 particles and $207 \mathrm{Bi}$ for electrons, placed in the same volume of liquid. The amount of recombination and gain in charge due to photosensitive substances is measured by comparing $\alpha$ and $\beta$ pulse heights as a function of dopant concentration. Saturation properties of the charge collection and the value of Birk's parameter at different concentrations are also measured.

In addition to radioactive sources, the use of a UV laser to extract free electrons from a photocathode facing the drift gap has many advantages. The UV laser provides a much higher number of primary electrons extracted from the photocathode ( $\approx 10^{6}$ electrons), compared to the much smaller signals given by the radioactive sources. A schematic representation of the test chambers is shown in Fig. 3.

\subsection{Laser cell}

A double-gridded chamber is used for the observation of the UV laserinduced electrons. The drift-time separating the two grids provides a direct measurement of the drift velocity for a given electric field. The cell is designed for a maximum field of $10 \mathrm{kV} / \mathrm{cm}$ in the central region. The electric fields in the cathode-grid and grid-anode gaps are respectively $5 \mathrm{kV} / \mathrm{cm}$ and $20 \mathrm{kV} / \mathrm{cm}$ (nominal) to ensure proper transparency of the grids. For such a configuration of field and geometry, the maximum high voltage is $30 \mathrm{kV}$. The grids are photoetched $\mathrm{Au}$ plated $\mathrm{Cu}-\mathrm{Be}, 100 \mu \mathrm{m}$ in diameter, and spaced by $1 \mathrm{~mm}^{2}$. The electrodes are stainless steel, except for the photocathode electrode, which is made of Au plated Cu. The UV optical fibre ( $1 \mathrm{~mm}$ core, Teflon coated) is guided through a hole in the photocathode and extracts electrons from a small inclined plane at $45^{\circ}$, machined in the middle of the electrode. The UV laser light of $266 \mathrm{~nm}$ wavelength is provided by a Nd:Yag laser with the proper optics to focus the beam at the input of the $1 \mathrm{~mm}$ diameter fibre. Signals from the cathode (after capacilive decoupling) and the anode are collected.

The ratio of the charges collected at the cathode and the anode is a measurement of the lifetime of the licjuid using the approximate formula:

$$
Q(\text { anode }) / Q(\text { cathode }) \approx \exp \left(-\mathrm{t}_{d} / \mathrm{T}\right) \text {, }
$$


where $T$ is defined as the 'liquid' lifetime. This lifetime has been shown to be inversely proportional to the amount of impurities [19]. With such a set-up, only a few laser pulses are necessary to obtain a precise measurement of the drift velocity and liquid lifetime. The lifetime is then used to correct the signals obtained from the radioactive sources.

\section{2. $\alpha$ and $\beta$ cells}

Radioactive sources are, of course, still necessary, as the laser set-up itself does not give any information about the primary ionization of the liquid. For the $\beta$ cell, a single-gridded ionization chamber is adequate with a $1 \mathrm{~cm}$ drift gap, which is sufficient to contain $1 \mathrm{MeV}$ radiation from the ${ }^{207} \mathrm{Bi}$ source. A gridded chamber was used in order to be independent of the direction of emission of the 8 particles. The electric field between the grid and the anode was $20 \mathrm{kV} / \mathrm{cm}$, nominal value.

For the of cell, a double-gridded chamber was used as in the UV laser cell, in order to try to perform the same measurements. We aimed with the source to measure not only the collected charge but as well the drift velocity and the lifetime, although signals are much smaller than in the laser case. In order to compare collected charges from and a sources, the field in the primary ionization region has to be identical. Field configuration for the $\alpha$ chamber was then: cathode-grid: $10 \mathrm{kV} / \mathrm{cm}$; drift region in between the grids: $20 \mathrm{kV} / \mathrm{cm}$; grid-anode: $40 \mathrm{kV} / \mathrm{cm}$. This very high field permitted us to check for any high voltage problems in doped liquid Ar. No unexpected discharges have been observed. Both $\alpha$ and $\beta$ sources are deposited on the cathodes. Their activities were around $1 \mathrm{kBq}$.

A detailed drawing of the set-up is given in Fig.4. The main components are manufactured with stainless steel, Teflon and ceramic. The detector is baked out under vacuum for several days at a maximum temperature of $120^{\circ} \mathrm{C}$ before operation.

\subsection{IR absorption cell}

At the bottom of the detector, a flange is provided for the foreseen addition of a section for IR absorption measurements, as shown in Fig. 5. This section contains 2 IR windows made of KRS-5 crystal on each side of the optical 
path (4 total).

Infrared spectroscopy allows the direct analysis of dissolved impurities in the liquid phase [20], as well as the measurement of the real concentration of dopant in the solvent. Dopants and impurities have absorption spectra in the IR region from $2-20 \mu \mathrm{m}$ as observed in the gas phase [21]. Their concentrations can thus be determined by measuring the absorption of a parallel IR beam passing through the liquid. The arrangement of the Bruker IFS-66 FT-IR spectrometer along with its external IR beam is shown in Fig. 6 [22].

\subsection{Vacuum tank and cryostat}

The detector was embedded in a vacuum tank connected to a cryostat (Fig.7). The cooling of the detector to liquid Ar temperature was performed by a cold finger in contact with liquid $\mathrm{N}_{2}$. In addition, a loop of circulating liquid $\mathrm{N}_{2}$ circled the top flange of the detector. Its purpose was twofold: it provided both additional cooling power during the Ar gas liquefaction phase and additional regulation capability. The flow of liquid $\mathrm{N}_{2}$ was controlled by an electromagnetic valve regulated by the chamber-internal pressure. The operation of the cryostat, cold finger, and liquid $\mathrm{N}_{2}$ flow proved to be very stable and convenient. The usual consumption was about 0.2 liters of $\mathrm{LN}_{2}$ /hour.

Argon gas was obtained from the evaporation of liquid Ar and passed through an OXISORB filter to remove oxygen. No further purification was needed in order to reach sufficiently good lifetimes. Ethylene was obtained in N35 quality and was not purified all all before mixing with Ar in the gas phase. Mixing before liquefaction was performed in the following way. First, approximately $1 / 3$ of the total capacity of the detector (3.31 liquid) was filled by liquefying pure Ar gas. The dopant was stored as a gas in a separate container of known volume at a pressure corresponding to the desired number of dopant molecules. Then, the remainder of the Ar gas was passed through the container before liquefaction. This method ensured that the total amount of dopant was flushed and liquefied along with the Ar in the detector. Once liquefied together with the Ar, the dopant did not escape back in the gas phase but stayed in the liquid phase. 


\subsection{Electronics}

The preamplifiers used were the ones developed for the UA1 and ICARUS experiments [23]. The UA1 preamplifier has a gain of $0.95 \mathrm{mV} / \mathrm{fC}$ at $50 \Omega$ and was used for the analysis of the laser pulses. Its rise-time is $100 \mathrm{~ns}$ and its decay-time is $110 \mu \mathrm{s}$, which were quite sufficient to hold the pulses during the entire drift-time. The ICARUS preamplifier has a higher sensitivity $(5.6 \mathrm{mV} / \mathrm{fC}$ at $50 \Omega$ ) and was used for the analysis of the source signals. Its rise-time is $40 \mathrm{~ns}$. The overall response of the electronics was measured with test pulses sent through capacitors. The shaping time used before multichannel analysis of the sources was $2 \mu \mathrm{s}$. Because the HV blocking capacitors had high values $(500 \mathrm{pF})$, corrections were applied to the data to take the loss of signal into account.

\section{Experimental results on ethylene in licuid Ar}

\subsection{Drift velocity and liquid lifetime}

Data on the drift velocity of electrons and the lifetime of the liquid were obtained from pulse-shape analysis of the laser-induced pulses. For each electric field value, the drift-time between the two grids of the laser chamber is a direct measurement of the drift velocity. Cathode and anode signals added together after capacitive decoupling provide such a time measurement.

The ratio of the anode signal to the cathode signal for a given drift-time is a measurement of the lifetime of the licjuid. With this set-up, we measured the typical lifetime for pure liquid Ar as 100 $\mu \mathrm{s}$; mixing with unpurified ethylene reduces it to around 10-20 $\mu \mathrm{s}$. N35 quality elhylene is guaranteed to have $\leq 200$ ppm oxygen content which corresponds to a limit on the lifetime of 15-20 $\mu \mathrm{s}$ using the equation in Ref. [19]. The measured lifetimes have been used to correct $\alpha$ and $\beta$ anode signals.

In Figs. 8 and 9, the data on drift velocity are presented for the different concentrations of ethylene. The values at $10 \mathrm{kV} / \mathrm{cm}$ have been obtained by extrapolation of the data using a simple power fit. As observed previously, a substantial increase of the drift velocity over that of pure liquid Ar is noticed, 
especially at high field strength. The drift velocity at constant electric field $(E=10 \mathrm{kV} / \mathrm{cm}$ in Fig.9) shows a non-linear dependence on the ethylene concentration (expressed in \% vol. liquid).

\subsection{Ionization}

Figures 10 to 13 show the charges coliected on the anode and cathode for the $241 \mathrm{Am} \alpha$ and $207 \mathrm{Bi} \mathrm{g}$ sources. The effect of the photosensitive ethylene is clearly seen on the collected charge for alpha particles. The response to various ethylene concentrations on the charge collection from the $p$ source does not show a similar behaviour and is almost independent of the amount of dissolved ethylene; at the highest concentration, the signal shows a tendency to decrease.

At low dopant concentrations, the pulse height for $\alpha$ particles rises from the value observed for pure liquid Ar to a maximum (below $200 \mathrm{ppm}$ ). The exact value of the maximum depends on the quantum efficiency of the ethylene for the $130 \mathrm{~nm}$ luminescence (around 20\% as measured in Ref. [14]). The maximum value is reached when all generated UV photons are converted into charge. At higher concentrations, the pulse height from ox particles decreases, reaching values well below that of pure liquid $\mathrm{Ar}$ as soon as the ethylene concentration is above $0.1 \% \mathrm{vol}$.

Such behaviour for highly ionizing particles has been observed elsewhere $[3,24]$ with methane as well as with ethylene. Such a decrease could be explained by two phenomena: first, a possible quenching of UV production by the hydrocarbon. Such an effect has already been observed in liquid Ar with the addition of $1 \%$ of $\mathrm{N}_{2}$ [13]. Second, the addition of hydrocarbons may create a shorter range of recombination, which, added to a large decrease in the attenuation length of the UV light, would result in a loss of pulse height. In comparison, the response to lightly ionizing particles is almost unaffected.

Comparing the cathode and anode signals from a particles in Figs.10a and $\mathrm{b}$, we notice that the anode signal is slightly larger than the cathode signal. The difference is independent of electric field. For the $200 \mathrm{ppm} \mathrm{C}_{2} \mathrm{H}_{4}$ concentration this difference is around $0.5 \mathrm{fC}$. This charge represents the amount of UV light travelling beyond the grid separating the drift gap from the cathode. From such considerations, we can deduce a value of $0.5 \mathrm{~mm}$ for the UV absorption length of $200 \mathrm{ppm} \mathrm{C}_{2} \mathrm{H}_{4}$, decreasing at higher concentrations. 


\subsection{Saturation}

In hadronic showers, recoil protons have energies in the range of a few $\mathrm{MeV}$. These protons are very densely ionizing. It is very important that their ionization be correctly measured for the best energy resolution and compensation. The effects of saturation of the ionization signals in liquid Ar doped with ethylene are unknown. One approach to this problem is to consider that saturation in liquids is the same as in scintillators. Following this hypothesis, one can rewrite Birk's law in terms of collected charge.

$$
\frac{\mathrm{d} Q}{\mathrm{~d} x}=\frac{C \mathrm{~d} E / \mathrm{d} x}{1+k B \mathrm{~d} E / \mathrm{d} x}
$$

where $Q$ is the collected charge.

The constant $k B$ can be determined by only two different values of $\mathrm{d} E / \mathrm{d} x$, namely, the values for $\mathrm{d}$ and $F$ particles. It has never been shown, however, that doped licpuid Ar would obey Birk's law. Obviously, with only two points, the relevance of this law cannot be checked here.

Figures 14 and 15 show the value of $k B$ for different electric fields and ethylene concentrations. The values at $10 \mathrm{kV} / \mathrm{cm}$ have been obtained by extrapolation of the dalat. Addition of ethylene reduces the saturation properties, especially at low fields where recombination is important. Further reduction would be obtained by doping liquid Ar with concentrations below $200 \mathrm{ppm}$. Such results have been obtained by doping liquid Ar with very small amounts of allene [25]. On the other hand, the addition of as much as $0.5 \%$ vol. $\mathrm{C}_{2} \mathrm{H}_{4}$ multiplies $k B$ by a factor of 4 . The consequences of such a change on the energy resolution and compensation of a specific calorimeter would have to be evaluated for each absorber, gap thickness, and geometry. 


\section{Discussion}

The present data lead us to the following remarks. Two regimes of operation for doped liquid Ar calorimeters can be envisaged.

At low concentrations ( $\leq 200 \mathrm{ppm}$ ), no increase in drift velocity is expected; however, a large increase in the collected charge of $\alpha$ particles is measured. A value of saturation lower than for pure liquid Ar is consequently observed. This regime would correspond to better compensation between electron and hadron energy measurements in a hadron calorimeter.

At higher concentrations $(\geq 0.2 \%)$, on the contrary, the drift velocity is increased by a factor of 2 , but on the other hand, a degradation of the saturation properties of the mixture is observed. This regime is appropriate for a calorimeter in which it is important to collect as much charge as possible from minimum-ionizing particles for a given shaping time. Since most of the particles in electromagnetic showers are minimum-ionizing, such a concentration can be considered for faster electromagnetic calorimeters.

Simultaneously increased speed and better compensation is excluded in the case of $\mathrm{C}_{2} \mathrm{H}_{4}$, as shown by the data. Similar results are expected for any hydrocarbon, such as allene, propylene, etc.

\section{Implications on the monitoring of a LHC calorimeter}

In the case of a calorimeter using pure liquid $\mathrm{Ar}$ and full charge collection, the monitoring scheme has to be able to follow the $\mathrm{O}_{2}$ content of the liquid and to correct for the variation of the liquid lifetime. This can be realized with a single ionization chamber using an a source such as ${ }^{24 \mathrm{I}} \mathrm{Am}$. If a liquid $\mathrm{Ar}$ calorimeter using a very short shaping time such as $20 \mathrm{~ns}$ instead of full charge collection is considered, precise calibration of the electronic chain is required in addition[8].

In the case of a doped licuid Ar calorimeter, it is necessary to monitor additional variables such as the drift velocity and saturation properties in addition to the correction for the possible variation of the liquid lifetime. 
Unfortunately, a monitoring scheme with radioactive sources using very short shaping times is impossible because the collected charge would be too small. Furthermore, as was shown previously, the response of a doped liquid Ar calorimeter to highly and lightly ionizing particles is different. For this reason, the liquid lifetime has to be measured by means other than sources in order to apply a correction independent of any specific ionization.

The major difficulty in monitoring is the exact measurement of the drift speed. If a systematic error $\leq 1 \%$ is required in the charge measurement sampled at $20 \mathrm{~ns}$ peaking time, the total drift-time has to be measured to an equivalent precision, below $3 \mathrm{~ns}$ in the case of a calorimeter doped with $0.2 \%$ vol. $\mathrm{C}_{2} \mathrm{H}_{4}$ using a $2 \mathrm{~mm}$ gap. Such a precision would certainly call for the use of laser calibration with pulses extracting nearly $1 \mathrm{pC}$ of charge out of a cathode plane. The distribution of UV fibres through the different parts of a large calorimeter, as well as dedicated feedthroughs through the vacuum tank and detector walls, would be necessary.

An additional, fundamental difficulty at the LHC would be the secondary effects of radiation on the hydrocarbon. One expects that parameters such as the drift velocity and amount of charge collected would vary in the case of doped liquid Ar. The variation of such constants would certainly be very inhomogenous as a function of rapidity and radius from the interaction point, as the dose waries from the front to the back of a calorimeter as well as from the central barrel to the end-caps [7].

\section{Effects of racliation}

Radiation levels at LHC will reach levels of around $10^{5}$ Gy per year of operation at the tront of a calorimeter situated at $\eta=2$ and 2 meters away from the interaction point.

In the case of doped liquid Ar, the amount of solute would be so small that any direct effect of radiation on the clopant itself can be neglected. Damage to the bonds of the dopant molecules $(3.5-4.5 \mathrm{eV})$ is done by the action of free positive Ar ions, which are very reactive, as well as by the transfer of excitons from the excited Ar atoms to the molecules. Bolh processes can break hydrogen and 
carbon bonds. New radicals and new compounds are formed.

Defining $G\left(-\mathrm{C}_{2} \mathrm{H}_{4}\right)$ as the number of molecules of ethylene destroyed by $100 \mathrm{eV}$ of absorbed energy and $G(\mathrm{C}$-atoms $\leq 6)$ as the number of molecules with $\leq 6$ carbon atoms created by $100 \mathrm{eV}$ of absorbed energy, one notices that for $\mathrm{C}_{2} \mathrm{H}_{4}$ in liquid Ar solution [26] :

$$
\begin{aligned}
& G\left(-\mathrm{C}_{2} \mathrm{H}_{4}\right) \approx 14 \\
& G(\text { C-atoms } \leq 6) \approx 6.5-8
\end{aligned}
$$

The difference is due to the formation of larger molecules, such as vinyl, depending on the radiation level. It is probable that in the long run, products will be formed which cannot be removed from the calorimeter. Methane shows simpler radiolysis products [27].

One consequence of the destruction of the dopant molecules (estimated to $6 \times 10^{-2} \mathrm{ppm} \mathrm{C}_{2} \mathrm{H}_{4}$ destroyed/Gy from Holroyd [27]) is a variation of the characteristic parameters. In the case of a photosensitive dopant, a change of the amount of collected charge is expected. The radiolysis products of ethylene (such as acetylene, n-butane, ethane, etc...) are not photosensitive and do not contribute to any conversion of UV light into electrons. The dependence of electron drift velocity on the concentrations of most of the different radiolysis products is unknown, so any realistic prediction of the change of the drift velocity under the action of the radiation is hazardous.

To set-up a recirculation system at the same time able to remove undesirable radiolysis products and to add uniformly fresh dopant would be a very complicated operation, given the differences in liquefaction temperatures. In short, the overall problem of ensuring by adequate monitoring a systematic response of the entire calorimeter uniform to within $1 \%$ appears very difficult due to the high radiation environment. 


\section{Conclusion}

The present experiment has shown that the addition of ethylene to pure liquid Ar improves the drift velocity of electrons by at least a factor of two for ethylene concentrations $\geq 0.2 \% \mathrm{vol}$. The amount of charge collected from electrons from $207 \mathrm{Bi}$ is mostly unaffected by the dopant. Charge response to minimum-ionizing particles using very a fast shaping time of $20 \mathrm{~ns}$ then depends essentially on the drift velocity of free electrons in the gap.

The behaviour of the charge response to 0 particles from an $241 \mathrm{Am}$ source shows at low concentrations $(\leq 200 \mathrm{ppm})$ a large increase in charge collection due to the conversion of the UV luminescence of liquid Ar into electrons by the ethylene. However, at large concentrations, the signal falls below the response of pure liquid Ar resulting in an increase of the saturation properties of the mixture.

It has been demonstrated that it is not possible, even with a photosensitive substance such as ethylene, to get both effects at the same time: a significant increase of the drift velocity and a better response to highly ionizing particles such as alpha particles. A low dopant concentration is suitable to reach better compensation in a hadron calorimeter at the expense of getting no speed increase and a large dopant concentration can be envisaged for fast electromagnetic calorimeters. However, in a high radiation environment such as the LHC, a nonuniform degradation will be introduced by the radiation damage. This will result in major complications in the control and monitoring of systematic effects, counterbalancing possible benefits from photosensitivity or speed increase.

\section{Acknowledgements}

The authors would like to thank very warmly J.-C. Armand, A.Bochaton, R.Truhan and W.Wilkens from CERN for their invaluable help in building the apparatus, and the Surfaces and Materials Group of the MT Division at CERN for the use of the Bruker IFS-66 FT-IR spectrometer. 


\section{REFERENCES}

[1] P. Jenni, CERN 89-10 (1989) 69.

[2] C.W. Fabjan, CERN 88-02 (1988) 19.

[3] D. Rahm, Helios Collaboration, private communication.

[4] The CERN LHC Study Group : Design study of the large hadron collider (LHC), CERN 91-03.

[5] L. Fayard, presented to the ECFA study group on Calorimetry, and private communication.

[6] V. Radeka and S. Rescia, Nucl. Instrum. Methods A265 (1988) 228.

[7] G.R. Stevenson, ECFA LHC Workshop, CERN 90-10, ECFA 90-133 (1990), Vol 3, p. 566.

[8] B. Aubert et al., DRDC proposal P5, CERN/DRDC/90-31 (1990).

[9] L.S. Miller et al., Phys. Rev. 166 (1968) 871.

E. Shibamura et al., Nucl. Instrum. Methods $\underline{131}$ (1975) 249.

K. Yoshino et al., Phys. Rev. Al4, 1 (1976) 438.

U. Sowada and W.F. Schmidt, Can. J. Chem. 55 (1977) 1885.

T. Doke, Portugal Phys. 12 (1981) 9.

M. Chen et al., ECFA 89-124, CERN 89-10 (1989) 486.

[10] D.F. Anderson and D.C. Lamb, Nucl. Instrum. Methods A265 (1988) 440.

[11] S. Kubota et at., Phys. Rev. B13 (1976) 1649, B17 (1978) 2762, B20 (1979) 3486 and $\underline{\text { B21 }}$ (1980) 2632.

S. Kubota et al., Nucl. Instrum. Methods $\underline{150}$ (1978) 561 and 196 (1982)101.

S. Kubota et al., J. Phys. C.: Solid State Phys. 11 (1978) 2645.

A. Hitachi et al., Phys. Rev. B27 (1983) 5279.

T. Doke et al., Nucl. Instrum. Methods A235 (1985) 136. 
[12] D.F. Anderson, Nucl. Instrum. Methods A242 (1986) 254 and A245 (1986) 361.

S. Suzuki et al., Nucl. Instrum. Methods A245 (1986) 366 and Bulletin of Science and engineering Research Lab., Waseda University, Japan, 117 (1987) 89.

K. Masuda et al., Nucl. Instrum. Methods A279 (1989) 560.

[13] A. Hitachi, J. Chem. Phys. $\underline{80}$ (1984) 745.

[14] A. Hitachi, Miniworkshop on Low-Counting and Space-Based Use of liquid Ar and LXe Detectors, Waseda University, Japan (1990).

[15] R.W. Vance and W.M. Duke : Applied Cryogenic Engineering, New York: Wiley, 1962 (University of Califomia engineering and physical sciences extension series).

E. Szczepaniec-Cieciak, B. Ciejek : Cryogenics, November 1979. V.Vuillemin, Technical note CERN RD-4 TN / 91-01(unpublished).

[16] W.H. Beattie et al., J. Phys. Chem. 86 (iy82) 4351.

[17] H. Koizumi et al., Radiat. Phys. Chem. $\underline{32}$ (1988) 111.

[18] P. Cennini el al., CERN DRDC-P6 proposat, 1990.

C.W. Fabjan, V. Vuillemin, Proceedings of the Miniworkshop on LowCounting and Space-Based Use of licpuid Ar and LXe Detectors, Waseda University, Japan (1990).

[19] A. Gonidec et al., CERN-EP / 88-36 (unpublished).

[20] S.M. Freund et al., Anal. Chem. 50 (1978) 1260.

C.R. Gruhn and W.B. Maier II. Nucl. Instrum. Methods 160 (1979) 55.

121] R.H. Pierson el al., Anal.Chem. 28 (1956) 1218.

M. Moulson et al., Technical Note CERN RD-4 TN/91-(22 (unpublished).

[22] D. Lacarrere, Technical Note (FRN MT-SM/DL/90)-()95/cl (unpublished). 
[23] C. Bacci et al. Nucl. Instrum. Methods A279 (1979) 169.

P. Cennini, ICARUS Collaboration, private communication.

[24] D. Rahm, presented at this conference.

[25] D.F. Anderson, FERMILAB-Conf-90/251 and Proc. Int. Conf. on Calorimetry in High Energy Physics, Fermilab (1990).

D.F. Anderson and N.A. Amos, FERM!'AB-Pub-91/99 (1991).

[26] F. Vendrell and V. Vuillemin, Technical Note CERN RD-4 TN 90/01 (unpublished).

R.A. Holroyd and R.W. Fessenden, J. Chem. Phys. 67 (1963) 2743.

N.V. Klassen, J. Chem. Phys. 71 (1967) 2409.

[27] H.A. Gillis, J. Chem. Phys. 71 (1967) 1089.

N.V. Klassen, J. Chem. Phys. 71 (1967) 1076.

R.A. Holroyd, IEEE Trans.on Nucl. Science 37 (1990) 513. 


\section{LIST OF FIGURES}

Fig.1 : Maximum molar concentration of unsaturated hydrocarbons at $90 \mathrm{~K}$ in liquid $\mathrm{O}_{2}$ as a function of their melting points [15].

Fig. 2 : Maximum molar concentration of unsaturated hydrocarbons at $90 \mathrm{~K}$ in liquid $\mathrm{O}_{2}$ as a function of their number of carbon atoms [15].

Fig.3 : Schematic representation of the ionization chambers used in the present test set-up.

Fig.4 : Schematic drawing of the detector.

Fig.5 : Schematic drawing ol the IR absorption test cell.

Fig.6 : Diagram of the IR spectrometry station using a BRUKER IFS-66 FT-IR spectrometer with an extemal beam extension and separate detector.

Fig.7 : Schematic drawing of the detector together with the vacuum tank, cryostat and cell for IR measurements.

Fig. 8 : Drift velocity of electrons in liquid Ar doped with ethylene as a function of the electric field for several concentrations. Superimposed curves are simple power fit lines.

Fig.9 : Drift velocity of electrons in liquid Ar doped with ethylene as a function of dissolved elhylene concentration.

Fig.10: Charge collected on the citthode (a) and on the anode (b) from the 241 Am a source in licpuid Ar doped with ethylene as a function of electric ficld for several concentrations. In both figures superimposed curves are simple power-law fit lines.

Fig.11 : Charge from a ${ }^{241} \mathrm{Am}$ as source in liquid Ar doped with ethylene as a function of dissolved ethylene concentration.

Fig.12: Charge collected on the anode lrom a 207Bi $\beta$ source in liquid Ar 
doped with ethylene as a function of electric field for several concentrations.

Fig.13 : Charge from a $207 \mathrm{Bi} / \mathrm{s}$ source in liquid Ar doped with ethylene as a function of dissolved ethylene concentration.

Fig.14 : Values of Birk's parameter obtained from $\alpha$ and $\beta$ collected charges in liquid $\mathrm{Ar}$ cloped with ethylene as a function of electric field for several concentrations.

Fig.15: Values of Birk's parameter obtained from and 8 collected charges in liquid Ar doped with elhylene as a function of dissolved ethylene concentration. 
Table 1: Solubilities of unsaturated hydrocarbons

\begin{tabular}{|c|c|c|c|c|}
\hline Compound & Formula & $\begin{array}{l}\text { Melting point } \\
\left({ }^{\circ} \mathrm{C}\right)\end{array}$ & $\begin{array}{l}\text { Solubility } \\
\text { (ppm in } \mathrm{LO}_{2} \text { ) } \\
\text { Vance, Duke }\end{array}$ & $\begin{array}{l}\text { Solubility } \\
\text { (ppm in } \mathrm{LO}_{2} \text { ) } \\
\text { Szczepaniec, ct. al. }{ }^{15}\end{array}$ \\
\hline Ethylene & $\mathrm{C}_{2} \mathrm{H}_{4}$ & -169 & 15000 & 19000 \\
\hline Propylene & $\mathrm{C}_{3} \mathrm{H}_{6}$ & -185.1 & 6000 & 6000 \\
\hline 1-Butene & $\mathrm{C}_{4} \mathrm{H}_{8}$ & -185.2 & 900 & 1000 \\
\hline Isobutene & $\mathrm{C}_{4} \mathrm{H}_{8}$ & -140.2 & 100 & 120 \\
\hline 1-Pentene & $\mathrm{C}_{5} \mathrm{H}_{10}$ & -165.2 & 150 & 240 \\
\hline 2-Pentene & $\mathrm{C}_{5} \mathrm{H}_{10}$ & -178.9 & 70 & 52 \\
\hline 1-Hexene & $\mathrm{C}_{6} \mathrm{H}_{12}$ & -139.8 & 10 & 13 \\
\hline 1-Heptene & $\mathrm{C}_{7} \mathrm{H}_{14}$ & -118.9 & - & -- \\
\hline 1-Octene & $\mathrm{C}_{8} \mathrm{H}_{16}$ & -101.7 & 3 & -. \\
\hline Acetylene & $\mathrm{C}_{2} \mathrm{H}_{2}$ & -80.6 & 6 & 5.7 \\
\hline
\end{tabular}


Table 2: Characteristics of some hydrocarbons as liquid argon dopants

\begin{tabular}{|c|c|c|c|c|c|c|}
\hline Compound & Formula & $\begin{array}{l}\text { Boiling } \\
\text { Point } \\
\left({ }^{\circ} \mathrm{C}\right)\end{array}$ & $\begin{array}{l}\text { Melting } \\
\text { Point } \\
\left({ }^{\circ} \mathrm{C}\right)\end{array}$ & $\begin{array}{l}\text { Ionization } \\
\text { Potential } \\
\text { (cV) }\end{array}$ & $\begin{array}{l}\text { Elec. Dipole } \\
\text { Moment } \\
\text { (debyes) }\end{array}$ & $\begin{array}{l}\text { Quantum } 14,17 \\
\text { Efliciency } \\
(\%)\end{array}$ \\
\hline Propane & $\mathrm{C}_{3} \mathrm{H}_{8}$ & -42.1 & -189.7 & 11.1 & 0.084 & 0 \\
\hline 1-Butenc & $\mathrm{C}_{4} \mathrm{H}_{8}$ & -6.3 & -185.3 & 9.6 & 0.34 & 21 \\
\hline Propene & $\mathrm{C}_{3} \mathrm{H}_{6}$ & -47.4 & -185.2 & 9.73 & 0.366 & 22 \\
\hline Ethane & $\mathrm{C}_{2} \mathrm{H}_{6}$ & -88.6 & -183.3 & 11.5 & 0 & 0 \\
\hline Methane & $\mathrm{CH}_{4}$ & -164 & -182 & 12.6 & 0 & 0 \\
\hline Ethylene & $\mathrm{C}_{2} \mathrm{H}_{4}$ & -103.7 & -169 & 10.5 & 0 & 20 \\
\hline Isobutane & $\mathrm{C}_{4} \mathrm{H}_{10}$ & -11.7 & -1.59 .4 & 10.57 & 0.132 & $0^{*}$ \\
\hline Isobulene & $\mathrm{C}_{4} \mathrm{H}_{8}$ & -6.9 & -140.3 & 9.23 & 0.5 & 20 \\
\hline n-Bulane & $\mathrm{C}_{4} \mathrm{H}_{10}$ & -0.5 & -1.38 .4 & 10.63 & $\leq 0.05$ & ()* \\
\hline Pentene & $\mathrm{C}_{5} \mathrm{H}_{10}$ & 30 & -1.38 & 9.5 & -- & $10^{*}$ \\
\hline Allene & $\mathrm{C}_{3} \mathrm{H}_{4}$ & -34.5 & -136 & 10.16 & 0 & 55 \\
\hline 1-Butyne & $\mathrm{C}_{4} \mathrm{H}_{6}$ & 8.1 & -125.7 & 10.18 & 0.8 & $20 *$ \\
\hline TMA & $\left(\mathrm{CH}_{3}\right)_{3} \mathrm{~N}$ & 2.9 & -117.2 & 7.82 & 0.612 & 23 \\
\hline TEA & $\left(\mathrm{C}_{2} \mathrm{H}_{5}\right)_{3} \mathrm{~N}$ & 89.3 & -114.7 & 7.5 & 0.66 & 15 \\
\hline cis-2-Butcne & $\mathrm{C}_{4} \mathrm{H}_{8}$ & 3.7 & -138.9 & 9.13 & - & 22 \\
\hline trans-2-Butcne & $\mathrm{C}_{4} \mathrm{H}_{8}$ & 0.9 & -10.5 .5 & 9.13 & 0 & 24 \\
\hline 1,3-Buladiene & $\mathrm{C}_{4} \mathrm{H}_{6}$ & -4.4 & -108.9 & 9.07 & 0 & $20^{* k}$ \\
\hline Cyclohexene & $\mathrm{C}_{6} \mathrm{H}_{10}$ & 83 & -103.5 & 8.95 & - & $10^{*}$ \\
\hline TMS & $\left(\mathrm{CH}_{3}\right)_{4} \mathrm{Si}$ & 27 & -10() & 9.86 & 0.525 & $20 *$ \\
\hline TMG & $\left(\mathrm{CH}_{3}\right)_{1} \mathrm{Cic}$ & 78 & -88 & 9.25 & -- & $50^{*}$ \\
\hline Acctylcue & $\mathrm{C}_{2} \mathrm{H}_{2}$ & -80.8 & $-8 \times-4$ & 11.4 & 0 & () \\
\hline
\end{tabular}

* estimatcd 


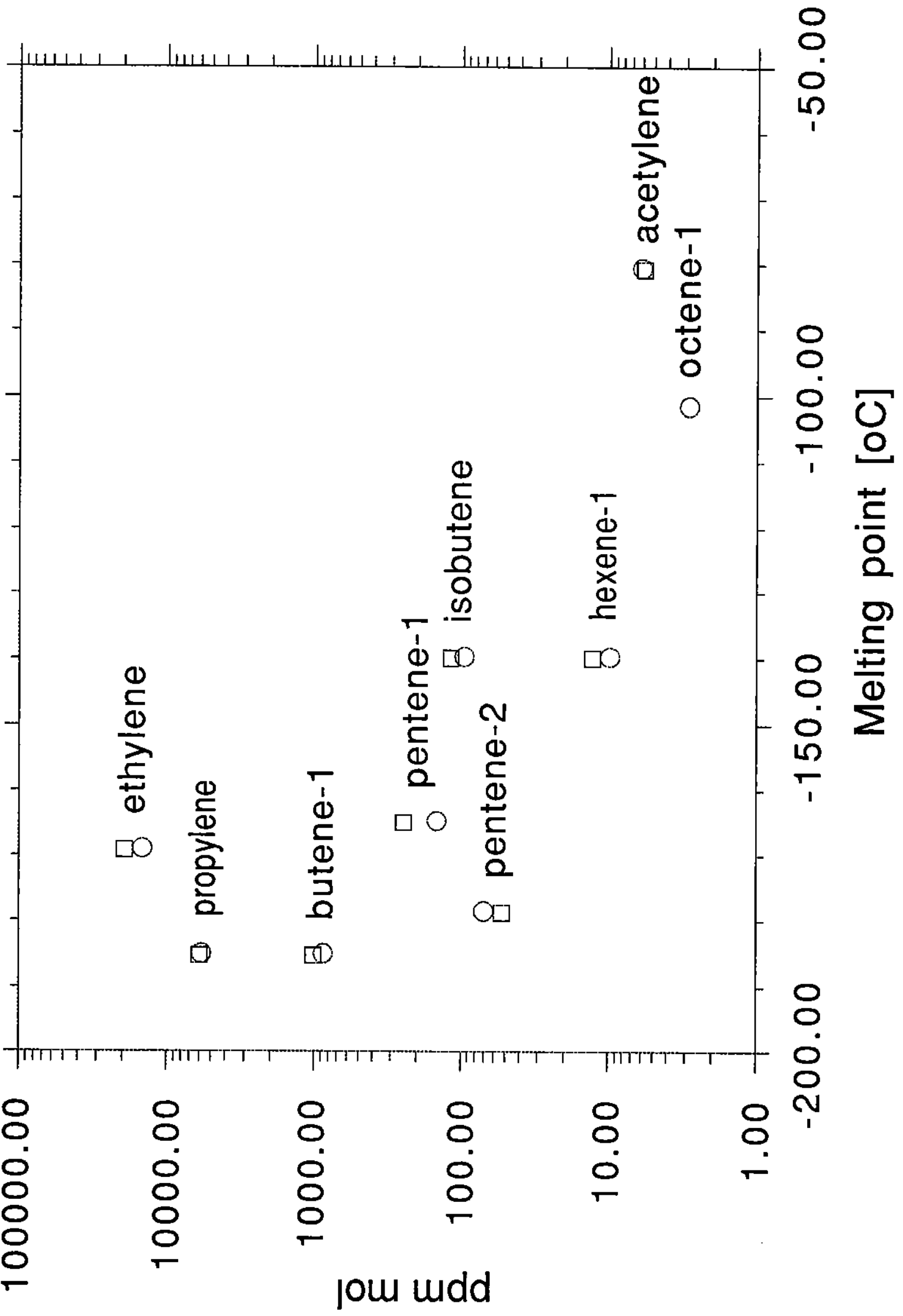




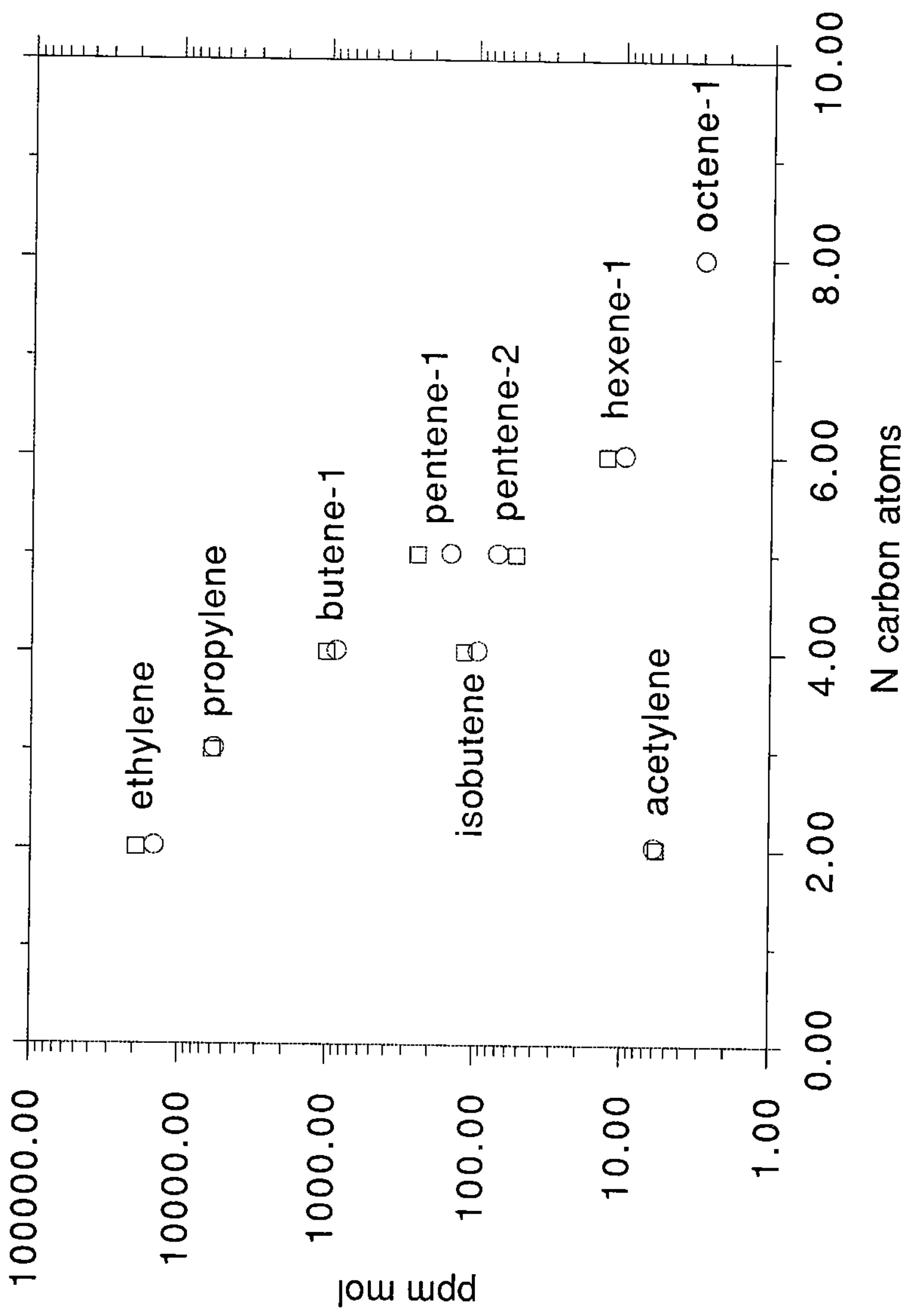



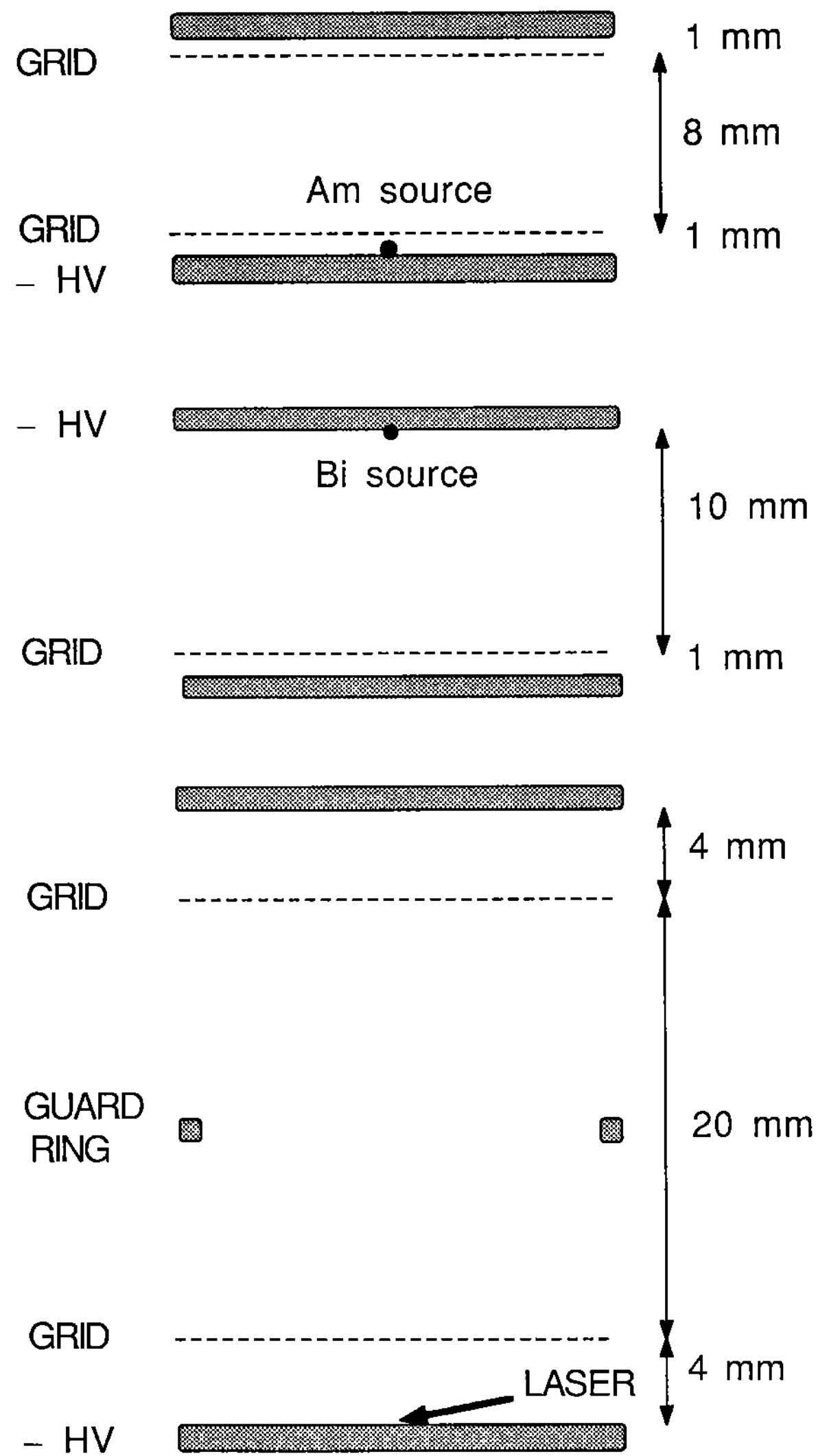

Fig. 3 


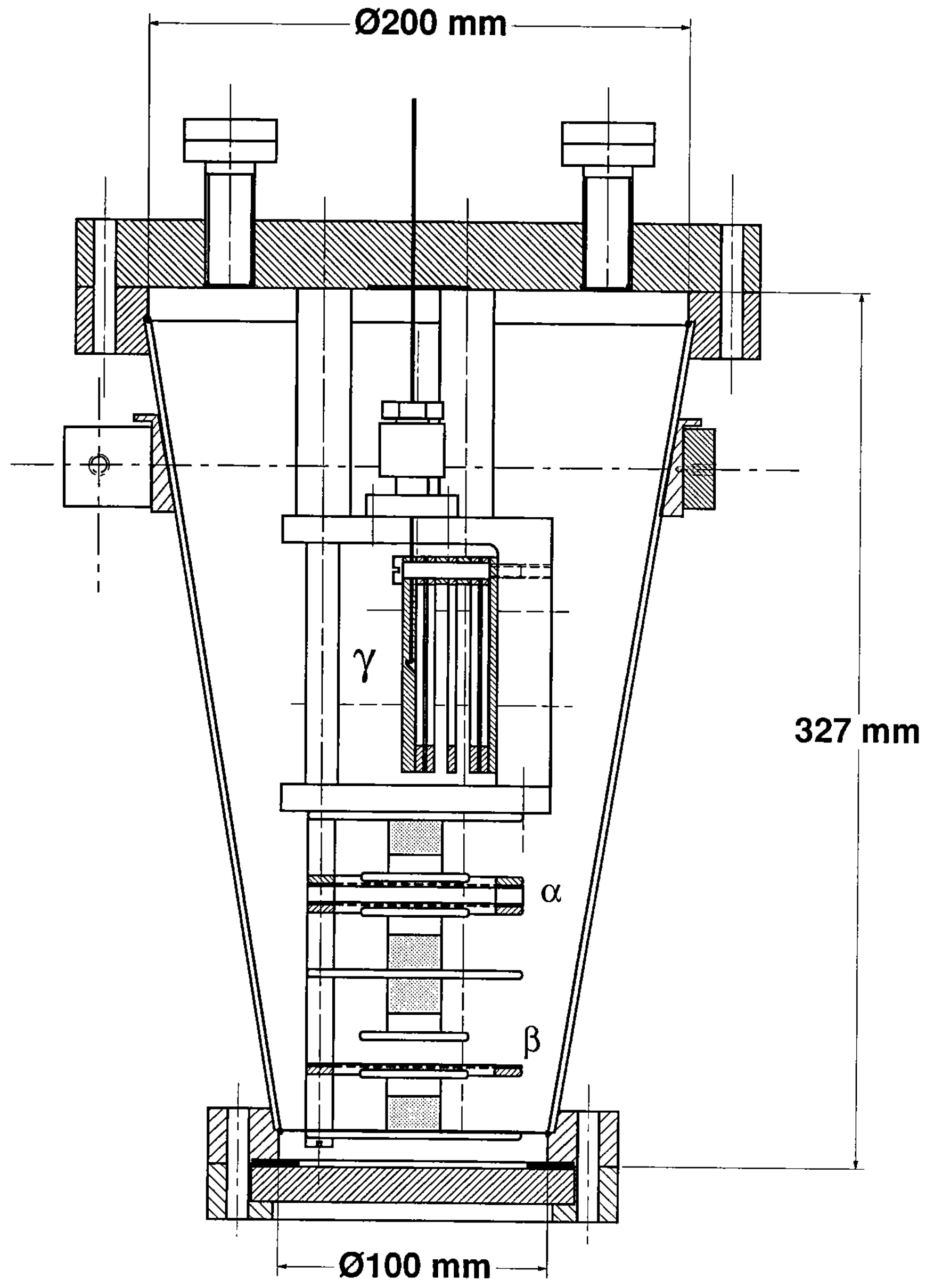

Fig. 4 

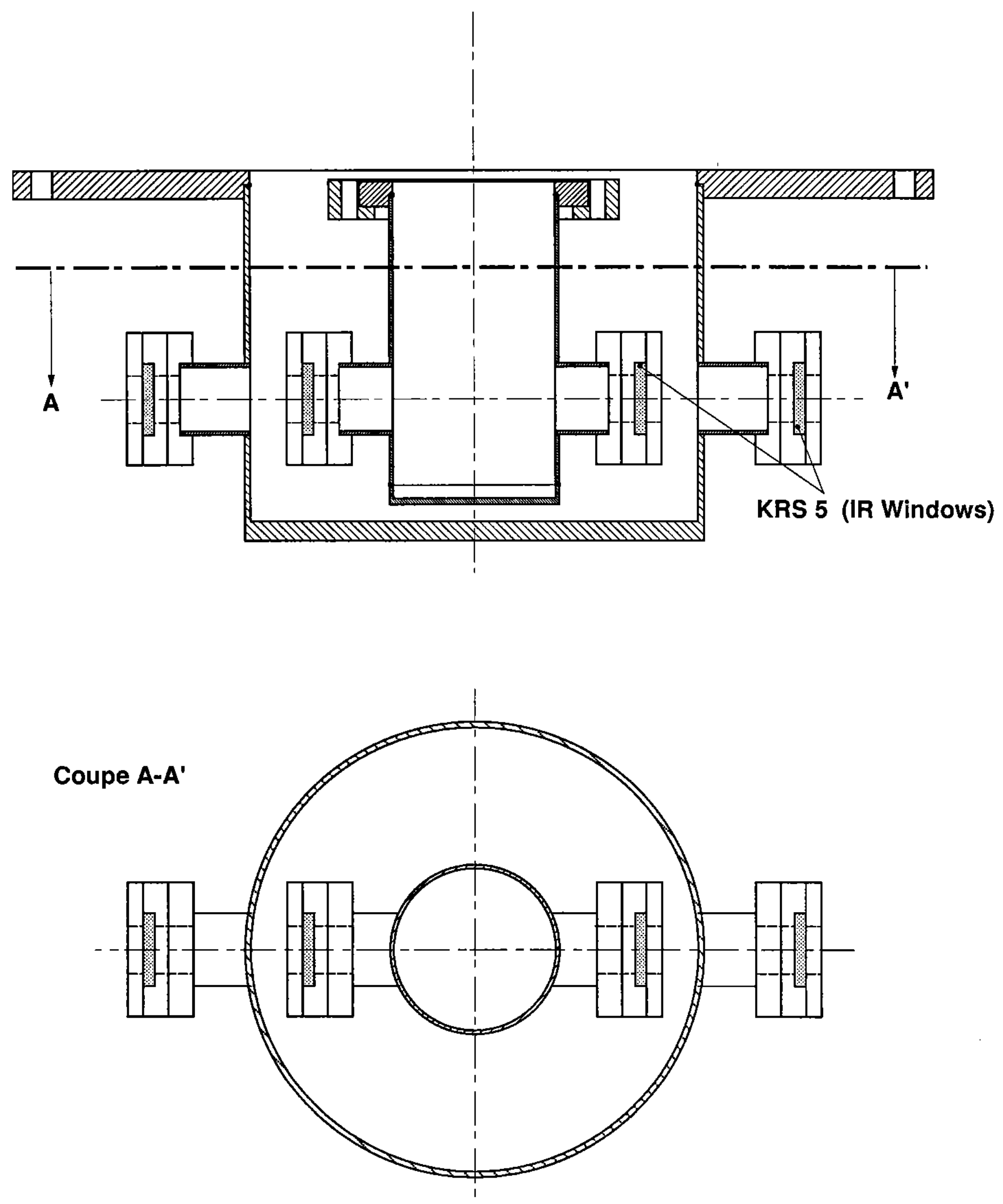

Fig. 5 
a) Top view

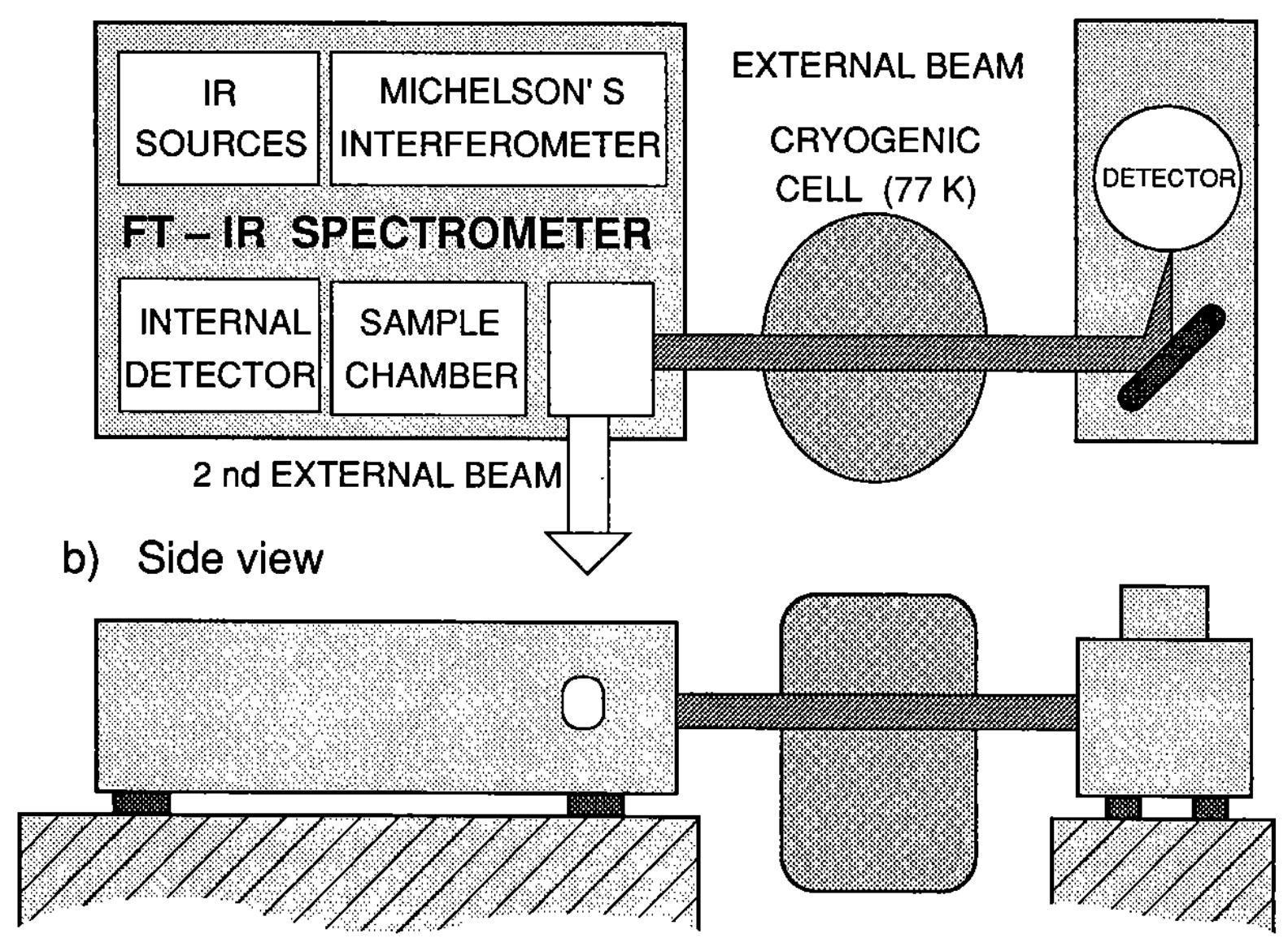

Fig. 6 


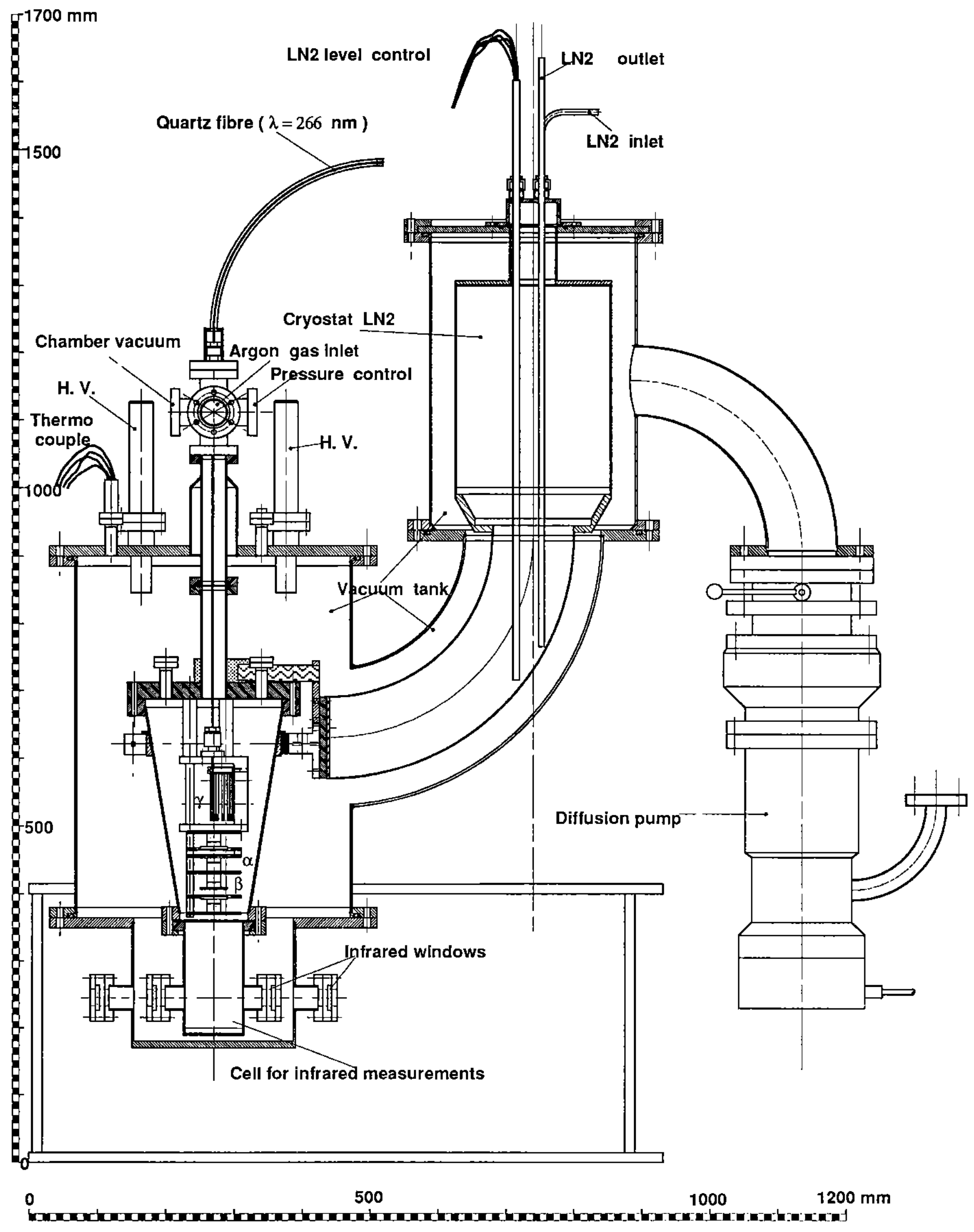

Fig. 7 

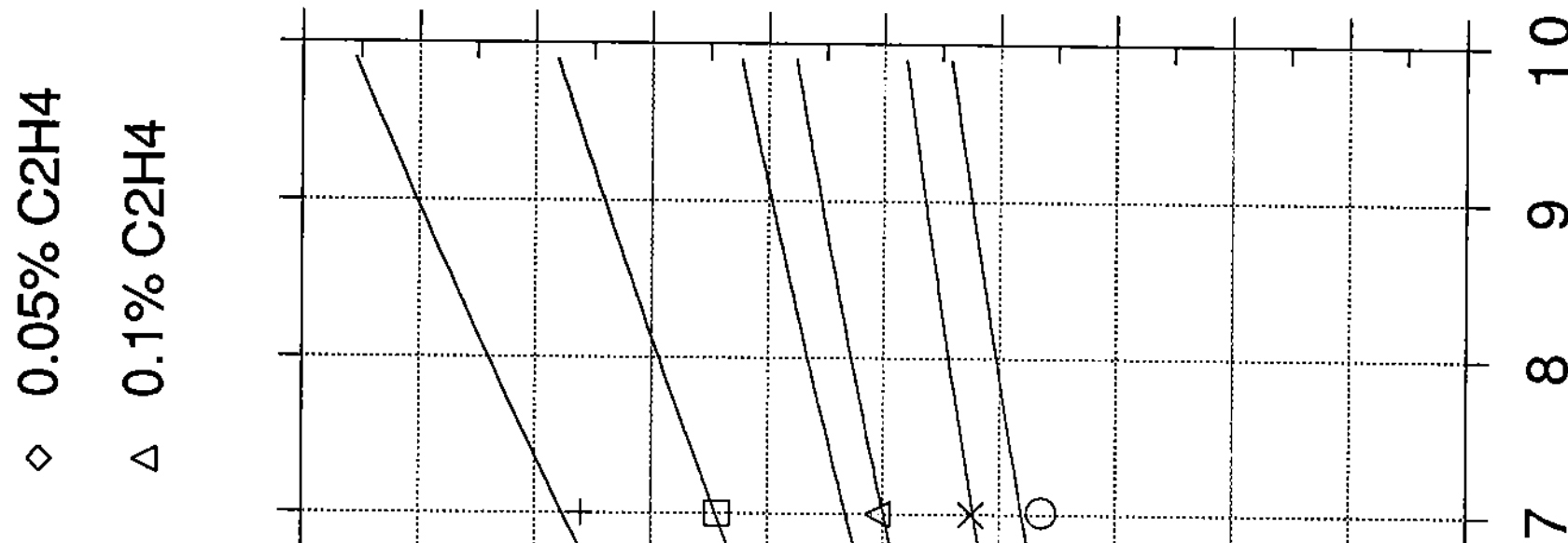

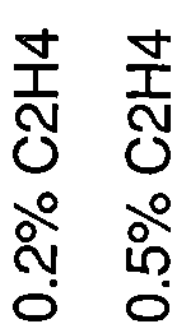

$\square+$

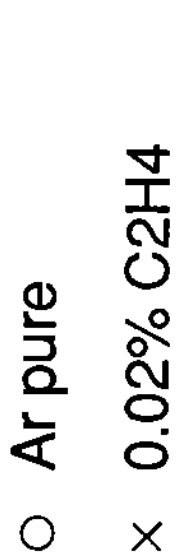

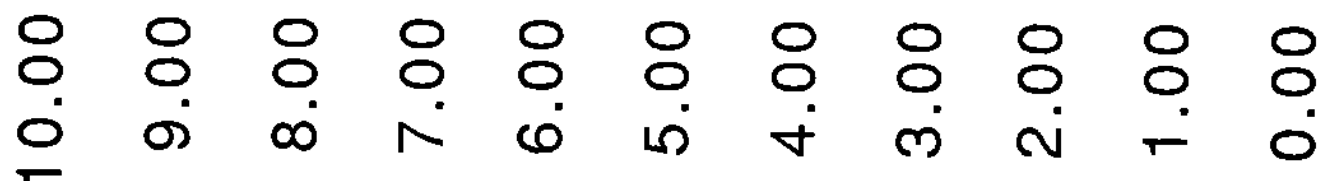

[ s/uO $G_{* *}$ OL ] H!!p $\wedge$ 


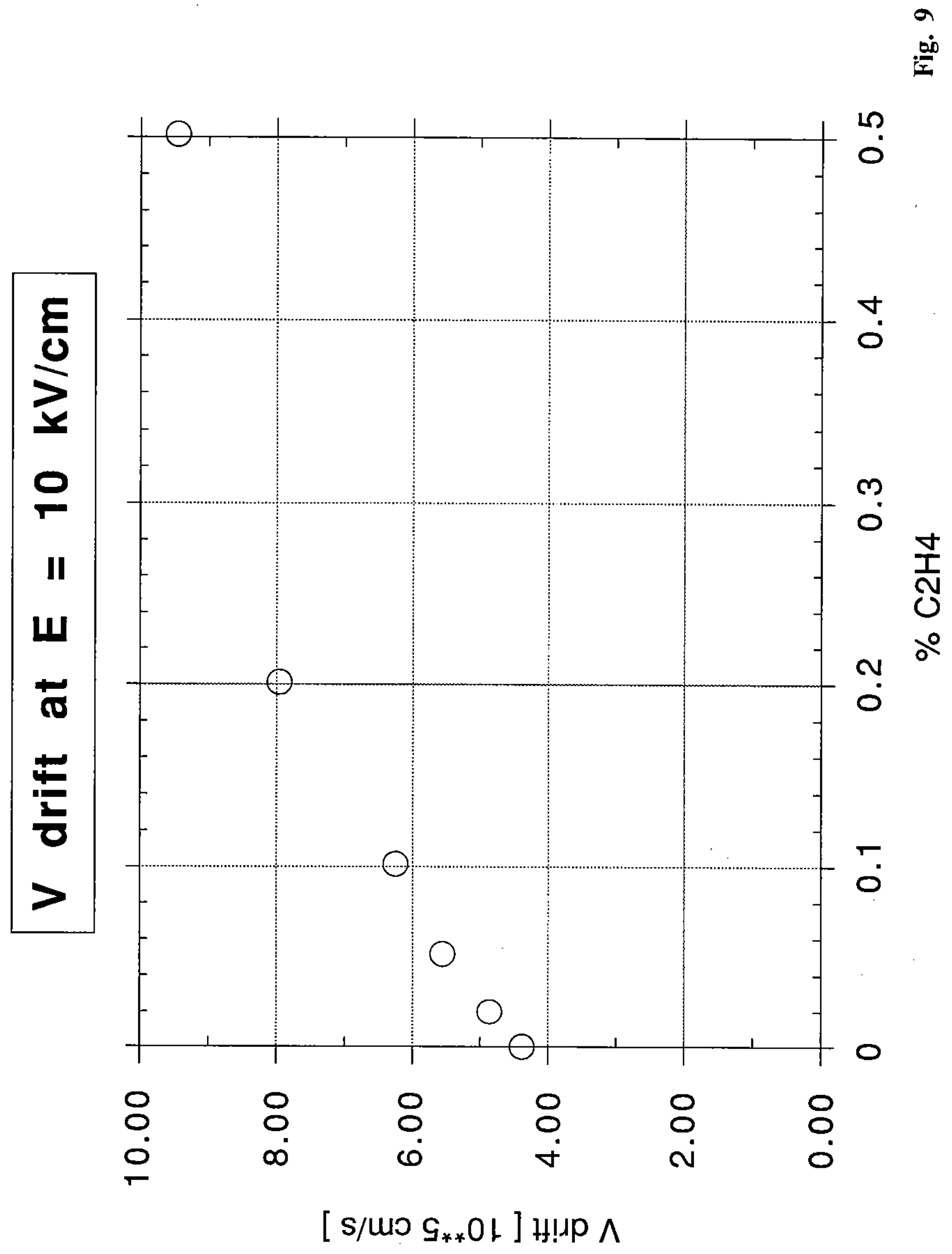


$\frac{1}{N}$
0
0
0
0
0
0

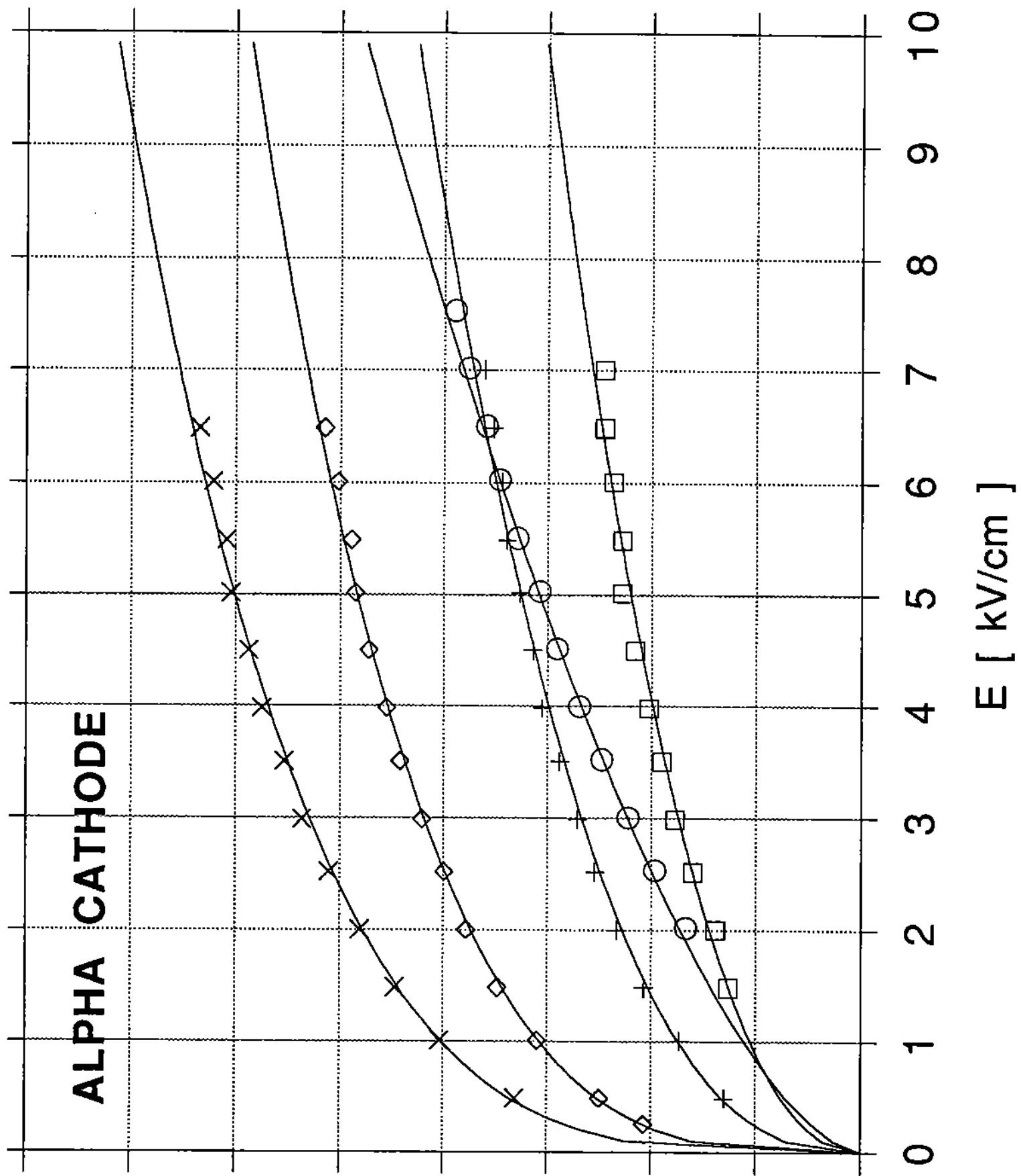

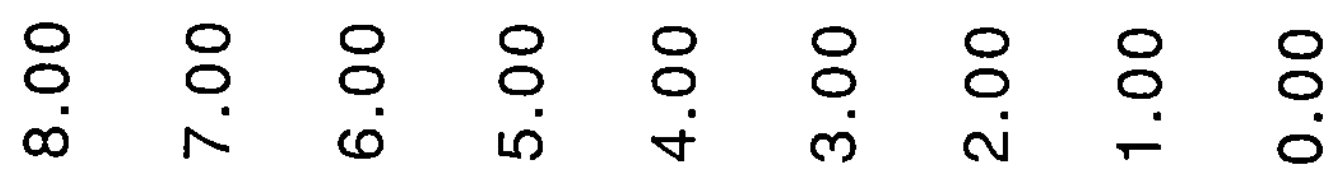

[ วิ] 0 


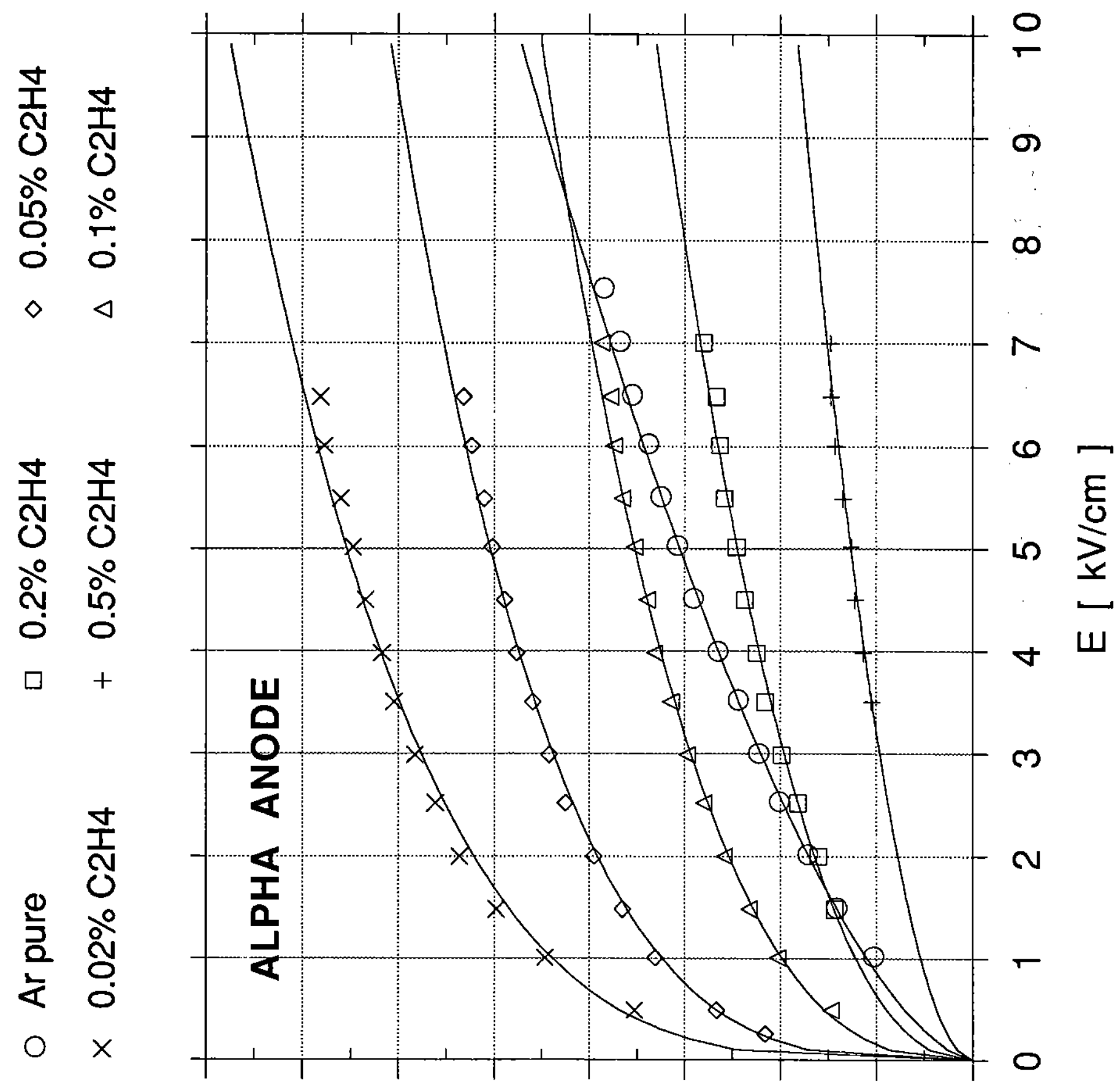

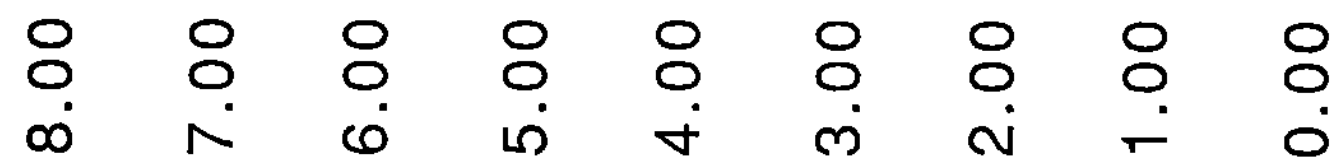

[ OH] O 


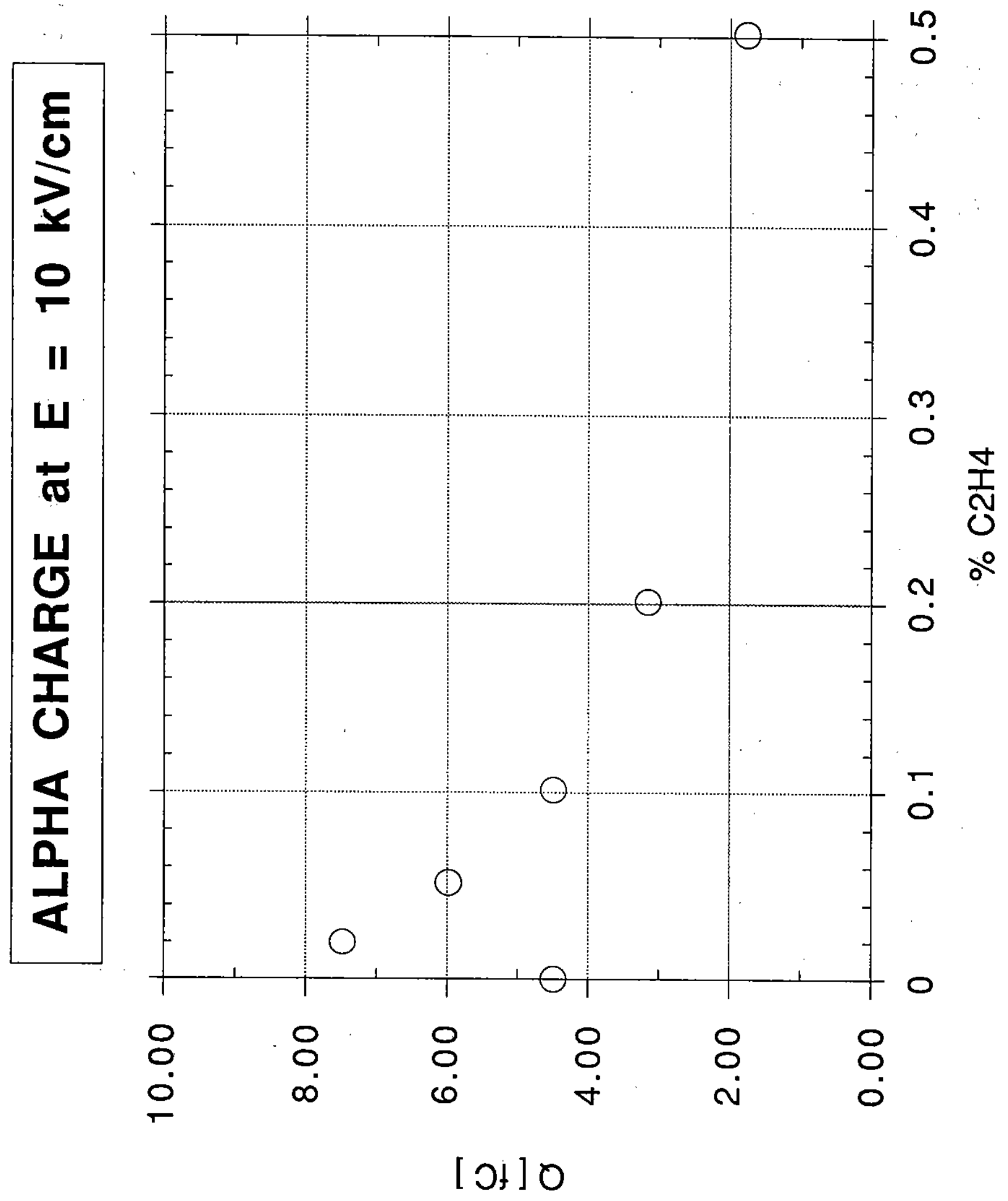




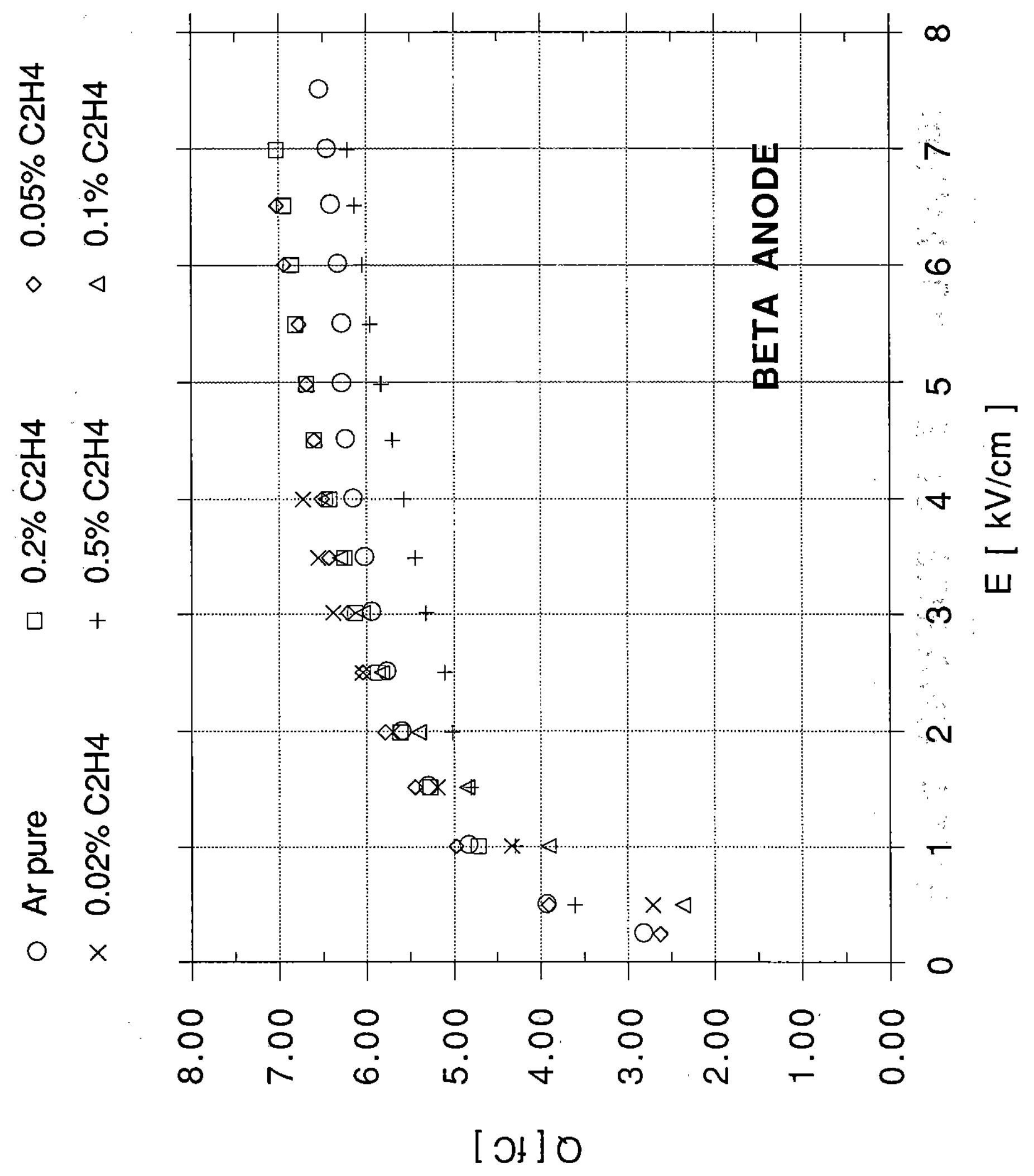


in

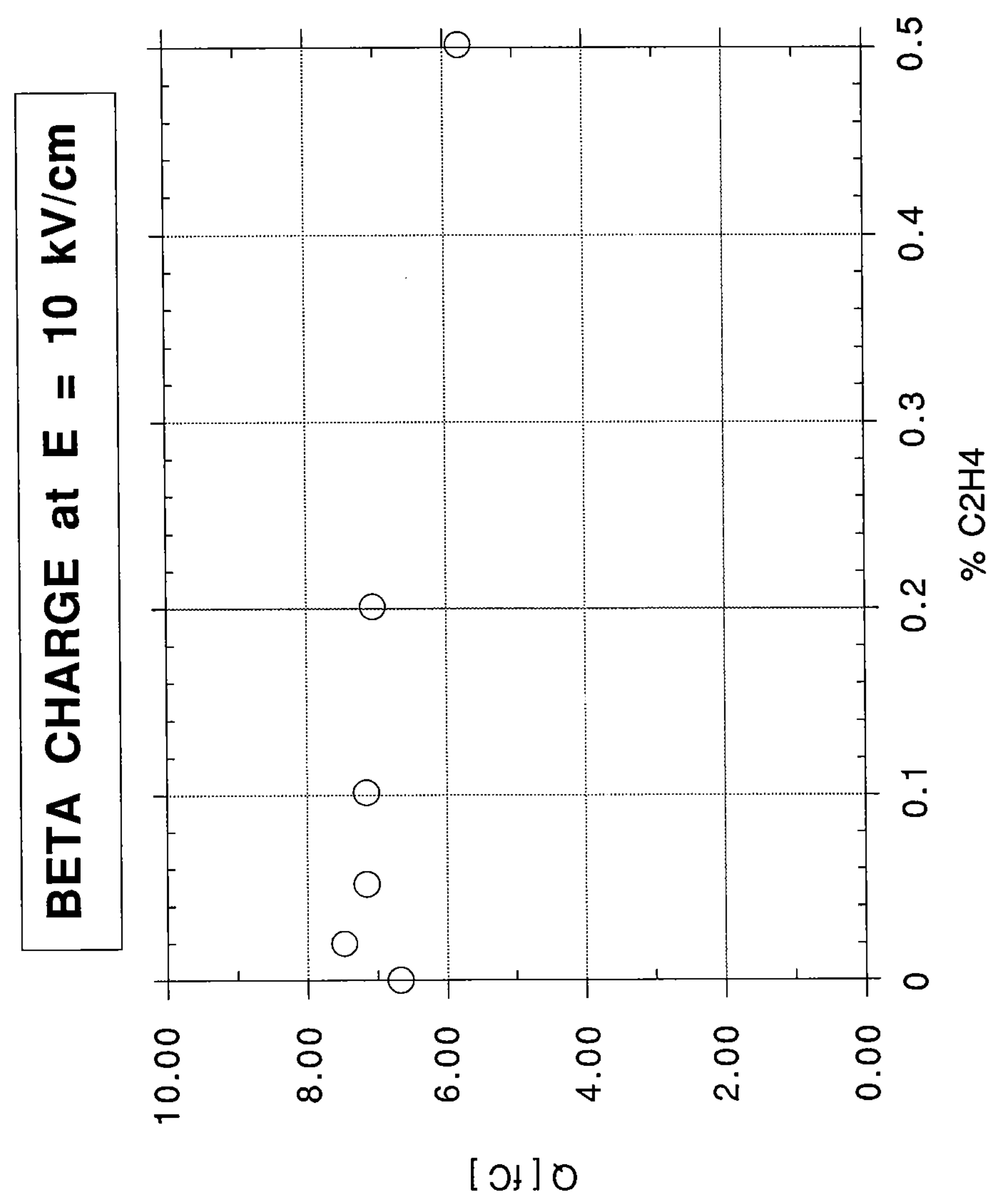




\section{$\underset{10}{ \pm 0}$}

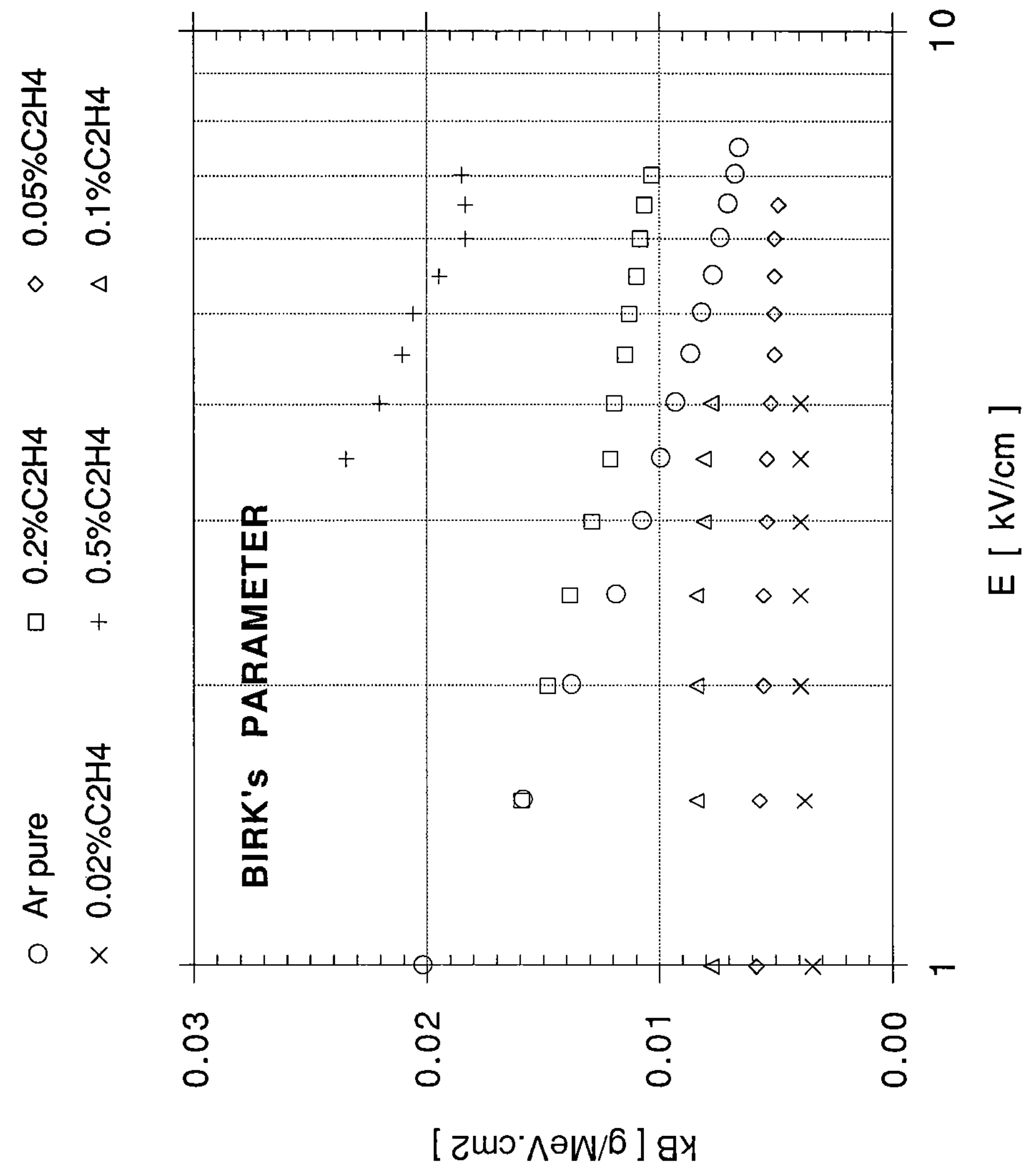




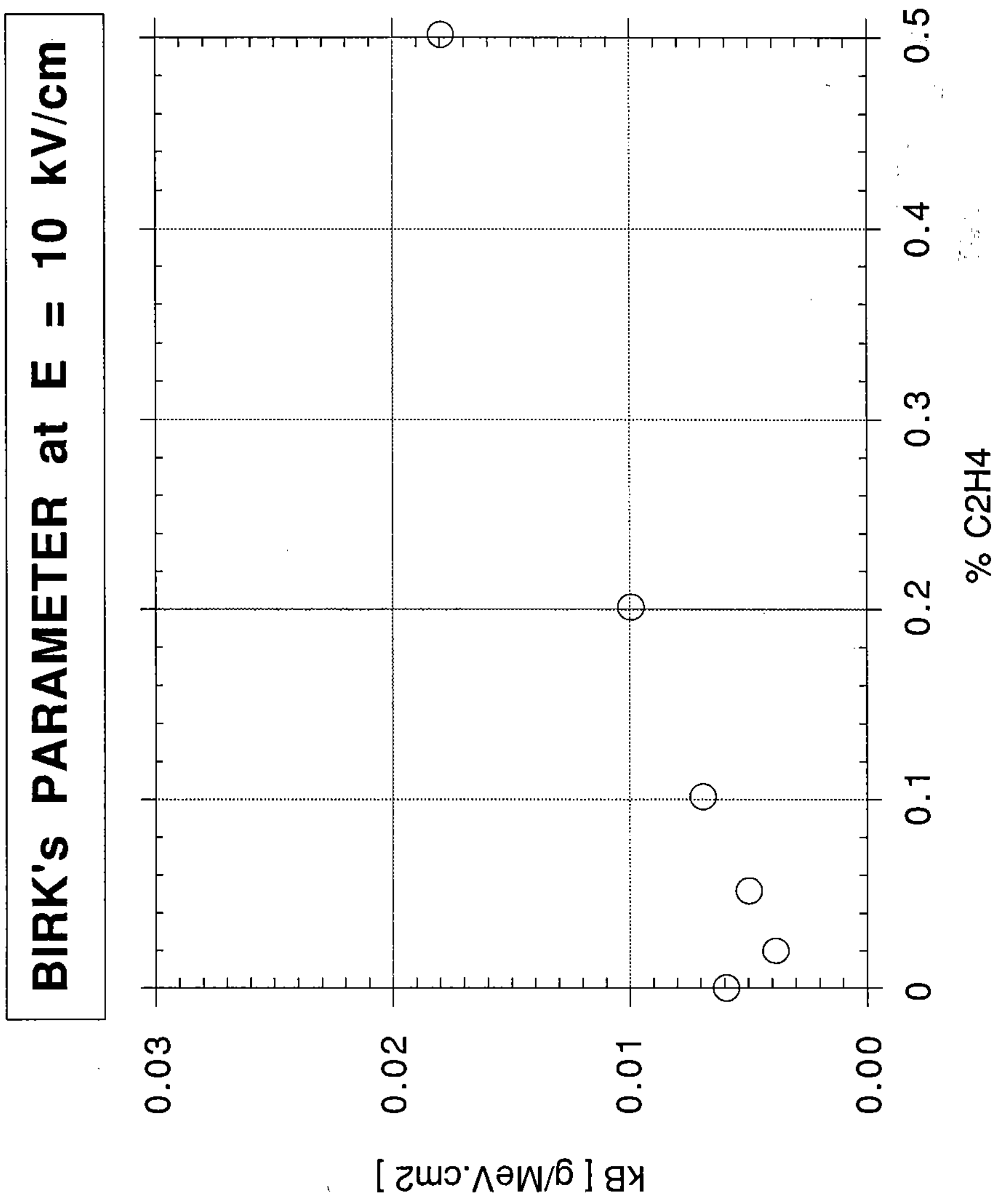

